\title{
Simple plasma assisted atomic layer deposition technique for high substitutional nitrogen doping of $\mathrm{TiO}_{2}$
}

Abdullah H. Alshehri, Nathan Nelson-Fitzpatrick, Khaled H. Ibrahim, Kissan Mistry, Mustafa Yavuz, and Kevin P. Musselman

Citation: Journal of Vacuum Science \& Technology A 36, 031602 (2018); doi: 10.1116/1.5019170

View online: https://doi.org/10.1116/1.5019170

View Table of Contents: http://avs.scitation.org/toc/jva/36/3

Published by the American Vacuum Society

\section{Articles you may be interested in}

Spatial atomic layer deposition for coating flexible porous Li-ion battery electrodes Journal of Vacuum Science \& Technology A: Vacuum, Surfaces, and Films 36, 01 A123 (2018); $10.1116 / 1.5006670$

Oxygen vacancy-passivated $\mathrm{ZnO}$ thin film formed by atomic layer deposition using $\mathrm{H}_{2} \mathrm{O}_{2}$ Journal of Vacuum Science \& Technology A: Vacuum, Surfaces, and Films 36, 031504 (2018); $10.1116 / 1.5012022$

Atomic layer deposition of $\mathrm{PbTiO}_{3}$ and $\mathrm{PbZr}_{x} \mathrm{Ti}_{1-x} \mathrm{O}_{3}$ films using metal alkyl and alkylamide precursors Journal of Vacuum Science \& Technology A: Vacuum, Surfaces, and Films 36, 031509 (2018); $10.1116 / 1.5014030$

Atomic layer deposition of amorphous Ni-Ta-N films for Cu diffusion barrier Journal of Vacuum Science \& Technology A: Vacuum, Surfaces, and Films 36, 031502 (2018); $10.1116 / 1.5002727$

Atomic layer etching of gallium nitride (0001) Journal of Vacuum Science \& Technology A: Vacuum, Surfaces, and Films 35, 060603 (2017); $10.1116 / 1.4993996$

Atmospheric pressure plasma enhanced spatial atomic layer deposition of $\mathrm{SnO}_{\mathrm{x}}$ as conductive gas diffusion barrier Journal of Vacuum Science \& Technology A: Vacuum, Surfaces, and Films 36, 01 A112 (2018); $10.1116 / 1.5006781$

This article may be downloaded for personal use only. Any other use requires prior permission of the author and AIP Publishing. The following article appeared in Alshehri, A. H., Nelson-Fitzpatrick, N., Ibrahim, K. H., Mistry, K., Yavuz, M., \& Musselman, K. P. (2018). Simple plasma assisted atomic layer deposition technique for high substitutional nitrogen doping of TiO2. Journal of Vacuum Science \& Technology A: Vacuum, Surfaces, and Films, 36(3), 031602 and may be found at https://doi.org/10.1116/1.5019170

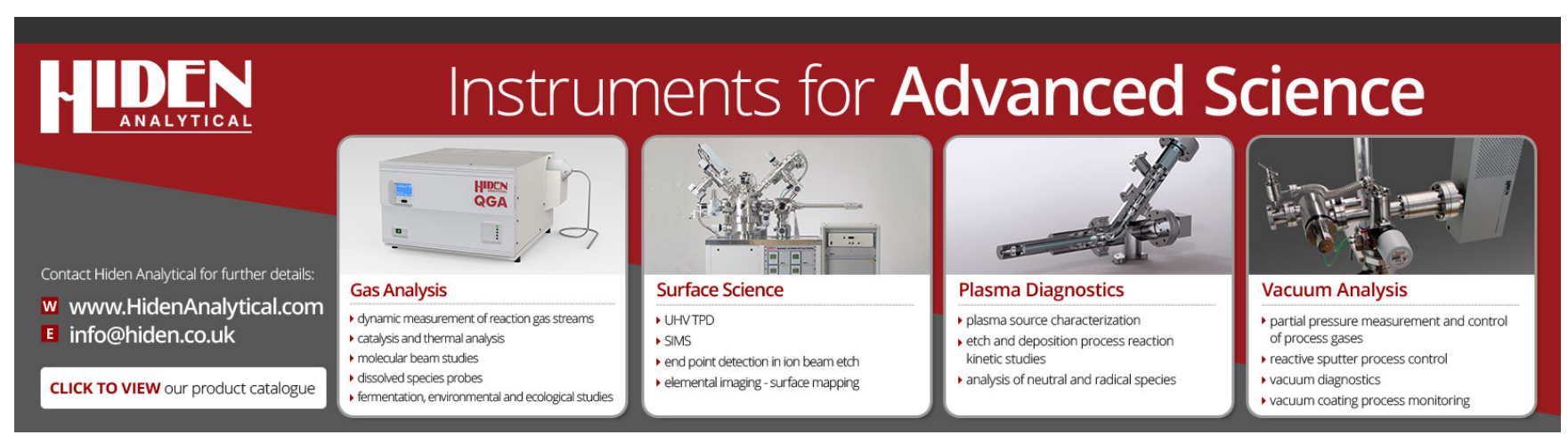




\title{
Simple plasma assisted atomic layer deposition technique for high substitutional nitrogen doping of $\mathrm{TiO}_{2}$
}

\author{
Abdullah H. Alshehri \\ Department of Mechanical and Mechatronics Engineering, University of Waterloo, 200 University Ave. West, \\ Waterloo, Ontario N2L 3G1, Canada and Department of Mechanical Engineering, Prince Sattam bin Abdul \\ Aziz University, Alkharj 11942, Saudi Arabia \\ Nathan Nelson-Fitzpatrick \\ Quantum NanoFab, University of Waterloo, 200 University Ave. West, Waterloo, Ontario N2L 3G1, Canada \\ Khaled H. Ibrahim, Kissan Mistry, Mustafa Yavuz, and Kevin P. Musselman ${ }^{\text {a) }}$ \\ Department of Mechanical and Mechatronics Engineering, University of Waterloo, 200 University Ave. West, \\ Waterloo, Ontario N2L 3G1, Canada and Waterloo Institute for Nanotechnology, University of Waterloo, \\ 200 University Ave. West, Waterloo, Ontario N2L 3G1, Canada
}

(Received 11 December 2017; accepted 26 February 2018; published 21 March 2018)

\begin{abstract}
In this work, a plasma assisted atomic layer deposition system was used to deposit nitrogen-doped titanium dioxide. A simple approach was developed that requires only a nitrogen plasma and short plasma exposure times to effectively dope $\mathrm{TiO}_{2}$. A range of nitrogen concentrations were achieved by varying the flow rate and exposure times of nitrogen and oxygen plasmas. A nitrogen content as high as $23 \pm 0.5$ at. \% was observed when only the nitrogen plasma was used. It was also possible to vary the type of nitrogen doping from almost entirely interstitial to purely substitutional, as measured by x-ray photoelectron spectroscopy. Ultraviolet-visible spectroscopy measurements showed a shifting in the absorption edge from 350 to $520 \mathrm{~nm}$ with doping, indicating bandgap narrowing from 3.1 to $1.9 \mathrm{eV}$. Published by the AVS. https://doi.org/10.1116/1.5019170
\end{abstract}

\section{INTRODUCTION}

Titanium dioxide $\left(\mathrm{TiO}_{2}\right)$ has been used for a variety of applications including sensors, ${ }^{1}$ photovoltaics, ${ }^{2}$ and photocatalysis for environmental and energy purposes (e.g., selfcleaning surfaces and water and air purification $)^{3,4}$ because it is chemically stable, cheap, abundant, and nontoxic. However, the large bandgap of the anatase form of $\mathrm{TiO}_{2}$ $(3.1 \mathrm{eV})$ limits the efficiency of photocatalysis under visible light, and the position of its conduction band influences electron transport in devices such as photovoltaics and metal-insulator-metal diodes. To enhance the photocatalytic efficiency of $\mathrm{TiO}_{2}$ and improve the current-voltage characteristics of $\mathrm{TiO}_{2}$ devices, ${ }^{5}$ nitrogen doping (N-doping) has been used to narrow the bandgap and increase visible light absorption. Various deposition processes have been used to introduce nitrogen atoms into the $\mathrm{TiO}_{2}$ lattice of nanoscale films. These have included sputtering, ${ }^{6}$ chemical vapor deposition, ${ }^{7}$ and atomic layer deposition (ALD). ${ }^{8}$ ALD has been used to deposit $\mathrm{TiO}_{2}$ thin films using water vapor and a variety of different precursors as the Ti source, including titanium tetrachloride $\left(\mathrm{TiCl}_{4}\right),{ }^{9}$ titanium tetrafluoride $\left(\mathrm{TiF}_{4}\right),{ }^{10}$ tetrakis (dimethylamino)-titanium (TDMAT), ${ }^{11}$ and titanium isopropoxide (TIIP). ${ }^{12,13}$ Much research on $\mathrm{N}$-doping with ALD has used $\mathrm{NH}_{3}$ gas or ammonia water. ${ }^{14,15}$ The use of an additional precursor introduces complexity, it can make it hard to control the nitrogen content, and the deposited film can change to TiN at high temperature. ${ }^{16,17}$ Recently, plasma assisted atomic layer deposition (PAALD) was used for doping due to advantages such as higher reactivity, low deposition temperature, ${ }^{18}$ and the possibility to control the

${ }^{a}$ Electronic mail: kevin.musselman@uwaterloo.ca chemical composition. ${ }^{17}$ However, these efforts resulted in low nitrogen contents or required complex techniques or relatively long deposition times to obtain high nitrogen contents. Zhipeng et al. ${ }^{19}$ deposited $\mathrm{N}$-doped $\mathrm{TiO}_{2}$ by PAALD with $\mathrm{TiCl}_{4}, \mathrm{H}_{2} \mathrm{O}$, and $\mathrm{N}_{2}$ plasma gas, achieving a doping level of 1 at. \% of nitrogen. Deng et al..$^{20}$ achieved a nitrogen content of 9.4 at. $\%$ by alternating thermal ALD of $\mathrm{TiO}_{2}$ and PAALD of TiN, but the use of alternating deposition methods required a longer deposition time. Zhang et al. ${ }^{17}$ deposited $\mathrm{TiO}_{2-\mathrm{x}} \mathrm{N}_{\mathrm{x}}$ ultrathin films by varying the background gas $\left(\mathrm{O}_{2}\right.$ or $\left.\mathrm{N}_{2}\right)$ during the Ti precursor exposure with a $\mathrm{N}_{2} / \mathrm{H}_{2^{-}}$ fed inductively coupled plasma (ICP). They achieved a significant nitrogen content of 13 at. \%, as measured at the surface of the film, and up to 22 at. \% in the bulk of the film by injecting $\mathrm{N}_{2}$ gas for $4 \mathrm{~s}$ through the ICP dosing line during the Ti precursor exposure. Despite using a procedure without any oxygen precursor, the substitutional doping in their films was limited to $50 \%$. Additionally, their approach used a long (15 s) $\mathrm{H}_{2} / \mathrm{N}_{2}$ plasma exposure time to achieve these nitrogen contents, which limits the film growth rate (up to $30 \mathrm{~s}$ required per cycle). Their approach is detailed schematically in Fig. 1. The PAALD cycle time is the sum of the Ti precursor dosing time, the Ti purge time, the reactant $\left(\mathrm{O}_{2} / \mathrm{N}_{2}\right)$ dose time, and the reactant plasma purge time. Thus, using more reactants and longer exposure times leads to increased purge times and increased cycle times, resulting in slow film growth rates. Furthermore, some of the previous reports of $\mathrm{N}$-doped $\mathrm{TiO}_{2}$ by PAALD used $\mathrm{TiCl}_{4}$ as the precursor, ${ }^{19}$ which is undesirable due to resulting chlorine contamination. Because chlorine and oxygen have different ionic radii, chlorine impurities result in undesirable chemical properties. ${ }^{21}$ Achieving $\mathrm{N}$-doped $\mathrm{TiO}_{2}$ with minimal contamination/ 


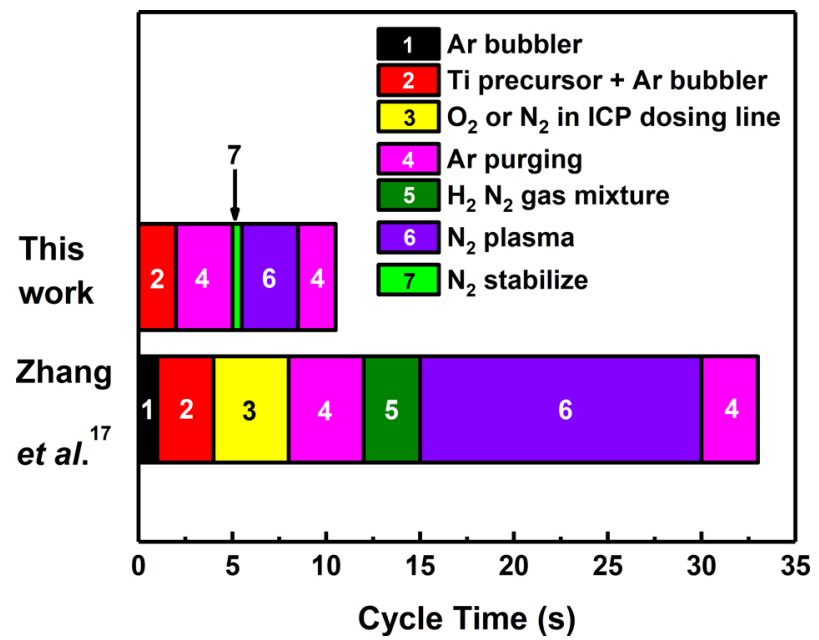

FIG. 1. (Color online) Flow chart of the PAALD cycle developed in this work and the cycle reported in previous work. Procedures that produced the highest nitrogen contents are shown.

impurities via faster depositions employing fewer precursors is challenging.

In this work, a simple and fast approach for PAALD of $\mathrm{N}$-doped $\mathrm{TiO}_{2}$ with a high nitrogen content and substitutional doping is designed and studied. Doping $\mathrm{TiO}_{2}$ with nitrogen requires high energy because breaking of $\mathrm{Ti}-\mathrm{O}$ bonds by nitrogen atoms is not thermodynamically favored. $^{20}$ Therefore, even when the nitrogen plasma flow was increased in PAALD previously, the nitrogen concentration in $\mathrm{TiO}_{2}$ was low. ${ }^{19}$ We use no $\mathrm{O}_{2}$ precursor sources and a pure nitrogen plasma (unlike the mixed $\mathrm{H}_{2} / \mathrm{N}_{2}$ plasma used by Zhang et al. ${ }^{17}$ ) in the approach presented here so that the formation of Ti-O bonds is inhibited and nitrogen is more likely to react with Ti. Residual water vapor in the PAALD chamber was an oxygen source in a pressure range of 1.3 $\times 10^{-4}$ to $1.3 \times 10^{-5} \mathrm{~Pa}$, and thus, titanium isopropoxide was selected as the titanium precursor because it is highly reactive with water vapor. Even though there is very little water vapor in the chamber as compared to nitrogen, its affinity for the $\mathrm{Ti}$ precursor is much greater, which is expected to ensure the formation of $\mathrm{N}$-doped $\mathrm{TiO}_{2}$ in this arrangement, rather than TiN. However, by limiting the quantity of oxygen present and using a pure $\mathrm{N}_{2}$ plasma, it is expected that nitrogen incorporation into the films will be enhanced and result in more substitutional doping of $\mathrm{TiO}_{2}$.

\section{EXPERIMENT}

\section{A. PAALD of $\mathrm{N}$-doped $\mathrm{TiO}_{2}$}

Nitrogen-doped $\mathrm{TiO}_{2}$ was deposited on silicon wafers (100 orientation) that were 2 in. in diameter and 13 to 17 thousandths of an inch (330 to $432 \mu \mathrm{m})$ thick, as identified by the manufacturer (Silicon Quest International), and glass substrates that were $25.4 \pm 0.2 \mathrm{~mm}$ in diameter and $1.6 \pm 0.2 \mathrm{~mm}$ thick. The depositions on the silicon and glass substrates were performed simultaneously in order to avoid any change in the deposition conditions. The films were deposited at $250{ }^{\circ} \mathrm{C}$ using an Oxford-FlexALTM system with a base pressure below $1.33 \times 10^{-4} \mathrm{~Pa}$. The moderate deposition temperature of $250{ }^{\circ} \mathrm{C}$ was selected to prevent the formation of TiN rather than $\mathrm{TiO}_{2}$. The system utilized an ICP source for remote plasma operation. The diameter of the ICP tube was $80 \mathrm{~mm}$, and the load lock of the system was pumped to below $1.33 \times 10^{-3} \mathrm{~Pa}$. The vacuum chamber was first purged with Ar for 3 min to stabilize the chamber pressure and temperature. Figure 1 illustrates the $\mathrm{N}$-doped $\mathrm{TiO}_{2}$ procedure used in this work, along with that of Zhang et al. ${ }^{17}$ TIIP bubbled with argon was used to dose the substrate for $2 \mathrm{~s}$ at a pressure of $10.6 \mathrm{~Pa}$, and then, the precursor line was purged with $\mathrm{Ar}$ for $3 \mathrm{~s}$ at a pressure of $2 \mathrm{~Pa}$. For some depositions, a flow of $\mathrm{O}_{2}$ was then stabilized for $500 \mathrm{~ms}$ before generating a plasma by radio frequency (RF) with a power of $300 \mathrm{~W}$ at a pressure of $2 \mathrm{~Pa}$. Selected substrates were exposed to the $\mathrm{O}_{2}$ plasma for $3 \mathrm{~s}$ and then purged with $\mathrm{Ar}$ for $2 \mathrm{~s}$ at a pressure of $10.6 \mathrm{~Pa}$. The $\mathrm{N}_{2}$ plasma flow was stabilized for $500 \mathrm{~ms}$, and a RF plasma was generated with a power of $300 \mathrm{~W}$. The substrates were exposed at a pressure of $2 \mathrm{~Pa}$ for different durations, followed by Ar purging for $2 \mathrm{~s}$ at a pressure of 10.6 Pa.

The $\mathrm{O}_{2}$ and $\mathrm{N}_{2}$ gas feeds, plasma exposure times, and number of PAALD cycles for different procedures tested are summarized in Table I. Notably, all procedures except the $\mathrm{TiO}_{2}$ procedure and the first doping procedure did not employ the oxygen plasma such that the only sources of oxygen were the TIIP and residual water vapor in the vacuum chamber.

\section{B. Characterization}

UV-Vis spectroscopy (UV-2501 PC) with a wavelength range of 190-1100 $\mathrm{nm}$, a resolution of $0.1 \mathrm{~nm}$, a wavelength accuracy of $\pm 0.3 \mathrm{~nm}$, and a precision of \pm 0.002 abs was applied to measure the transmittance $T$ and reflectance $R$ of the films, as shown in Fig. S1 in the supplementary material. $^{42}$ The extinction coefficient $k$ was calculated from the following relation: ${ }^{22,23}$

$$
k=-\ln [T /(1-R)][\lambda / 4 \pi d] .
$$

In Eq. (1), $\lambda$ is the wavelength and $d$ is the film thickness. The absorption coefficient $\alpha$ was then calculated using the extinction coefficient $k$,

$$
\alpha=[4 \pi k / \lambda]
$$

and the bandgaps of the films were determined using

TABLE I. Process procedures for PAALD films.

\begin{tabular}{lccccc}
\hline \hline \multirow{5}{*}{ Procedure } & \multicolumn{3}{c}{ Gas feed (sccm) } & & \\
\cline { 2 - 3 } & $\mathrm{O}_{2}$ & $\mathrm{~N}_{2}$ & Plasma time (s) & No. of cycles & Base pressure \\
\hline 1 & 10 & 50 & 3 & 600 & $1.33 \times 10^{-4} \mathrm{~Pa}$ \\
2 & 0 & 50 & 1 & 600 & \\
3 & 0 & 50 & 3 & 600 & \\
4 & 0 & 50 & 5 & 600 & \\
5 & 0 & 50 & 7 & 600 & \\
$\mathrm{TiO}_{2}$ & 60 & 0 & 3 & 600 & \\
\hline \hline
\end{tabular}




$$
\alpha h v=B\left[h v-E_{g}\right]^{r},
$$

where $B$ is a constant, $h v$ is the photon energy, $E_{g}$ is the bandgap of the material, and $r=2$ for an indirect bandgap, as reported previously. ${ }^{24}$ The bandgaps of the films were calculated from Tauc plots ${ }^{25}$ by plotting $(\alpha h v)^{1 / 2}$ versus the photon energy $h v$, where the tangent of the curve gives the bandgap of the film.

A Woollam M-2000 DI ellipsometer was used to measure the thickness of the films deposited on glass substrates for use in the bandgap calculations. Ellipsometry was also performed to measure the refractive indices of the films deposited on silicon wafers, where the deposited films were modeled using the Cauchy formula.

X-ray photo electron spectroscopy (XPS) (VG Scientific ESCALAB 250) was performed on the surface of the films using $\mathrm{Al} \mathrm{K} \alpha$ x-rays. The spectra were calibrated using the $\mathrm{C} 1 \mathrm{~s}$ peak at $284.6 \mathrm{eV}$. XPS was performed using silicon substrates rather than glass to obtain more reliable results.

\section{RESULTS AND DISCUSSION}

The absorption coefficients calculated from the UV-vis transmittance and reflectance measurements are shown in Fig. 2(a). A similar absorption edge is observed at approximately $350 \mathrm{~nm}$ for the films deposited using the $\mathrm{TiO}_{2}$ procedure and procedure 1 ( $3 \mathrm{~s}_{2}$ and $\mathrm{N}_{2}$ plasmas). A shift of the absorption edges to $450 \mathrm{~nm}$ for the second procedure (1s $\mathrm{N}_{2}$ plasma), $520 \mathrm{~nm}$ for the third procedure ( $3 \mathrm{~s} \mathrm{~N}_{2}$ plasma), and $500 \mathrm{~nm}$ for the fourth and fifth procedures $\left(5 \mathrm{~s}\right.$ and $7 \mathrm{~s} \mathrm{~N}_{2}$ plasmas) indicates the successful incorporation of nitrogen in all cases. Figure 2(b) shows the bandgaps identified using Tauc plots. The narrowing of the bandgap from $3.1 \mathrm{eV}$ for $\mathrm{TiO}_{2}$ to $1.9 \mathrm{eV}$ for the films deposited using the third procedure ( $3 \mathrm{~s} \mathrm{~N}_{2}$ plasma) is consistent with previous reports ${ }^{20}$ that showed narrowing of the bandgap to $1.91 \mathrm{eV}$.

The chemical composition and bonds between elements were characterized by XPS. Table II compares the XPS peak positions (Ti $2 p^{3 / 2}$, Ti $2 p^{1 / 2}, \mathrm{~N} 1 \mathrm{~s}$, and O1s) observed in this work with those of TiN, TiNO, and $\mathrm{N}$-doped $\mathrm{TiO}_{2}$ reported previously in the literature. It is seen that the peak positions measured here are consistent with $\mathrm{N}$-doped $\mathrm{TiO}_{2}$, rather than TiN or TiNO. To further confirm that $\mathrm{N}$-doped $\mathrm{TiO}_{2}$ was deposited, the refractive indices of the films were measured by ellipsometry. Figure S2 in the supplementary material shows that the refractive index values at $632.8 \mathrm{~nm}$ (start of the red part of the visible spectrum) were in the range of 2.4 to 2.9, consistent with previous reports that showed 2.4 (Ref. 23) and 2.9 (Ref. 26) for $\mathrm{TiO}_{2}$. The slight variation in the refractive index likely comes from composition changes in the $\mathrm{N}$-doped $\mathrm{TiO}_{2}$ films made using different procedures. In contrast, the refractive index of TiN is typically reported to be approximately $1.7 .^{22}$

Figure 3 shows the Ti $2 p$ XPS spectra of the films. Ti $2 p_{3 / 2}$ and Ti $2 \mathrm{p}_{1 / 2}$ peaks are located at $458 \mathrm{eV}$ and $464 \mathrm{eV}$, respectively, for the $\mathrm{TiO}_{2}$ procedure in Fig. 3(a), and are attributed to $\mathrm{TiO}_{2}\left(\mathrm{Ti}^{4+}\right)$. For procedure $1\left(3 \mathrm{~s} \mathrm{O}_{2}\right.$ and $\mathrm{N}_{2}$ plasmas), the same $\mathrm{Ti}^{4+}$ peaks are observed in Fig. 3(b). When a $\mathrm{N}_{2}$
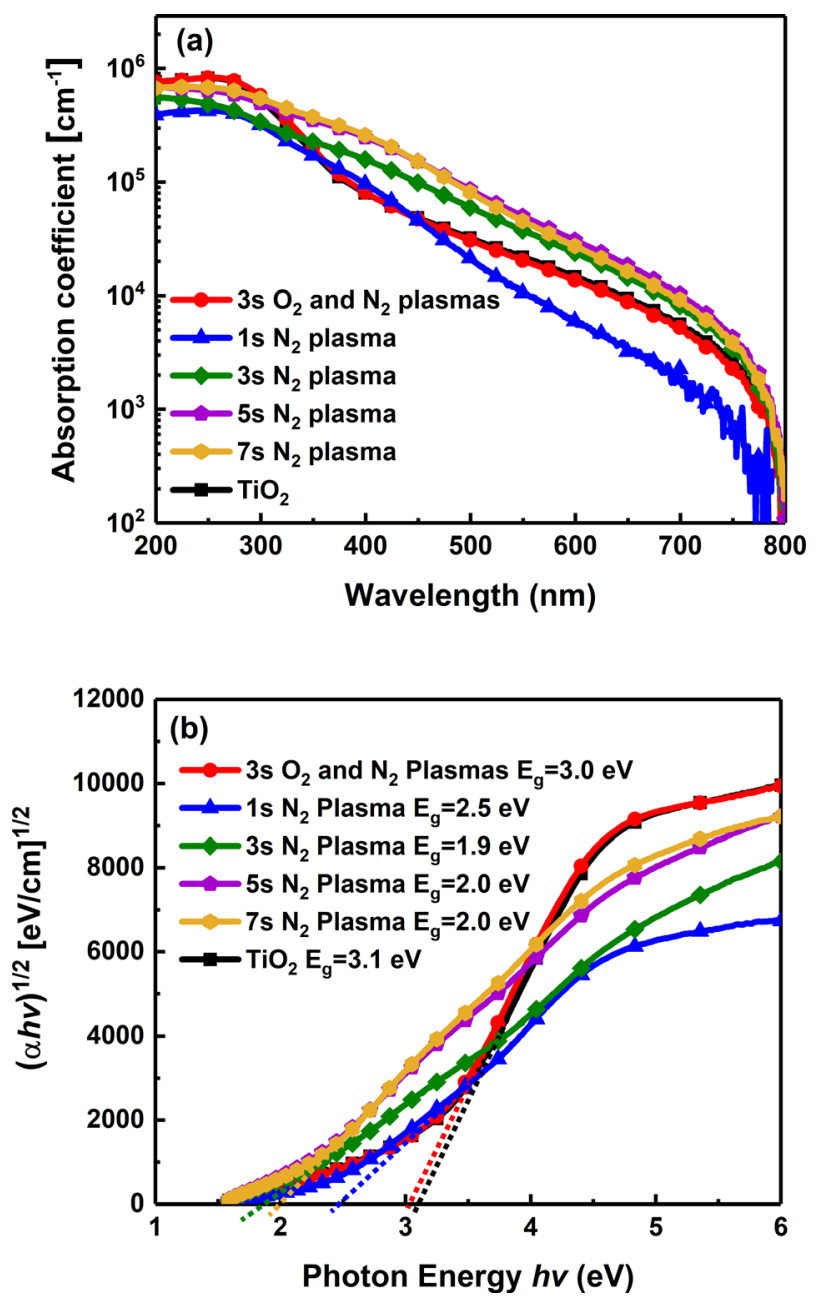

FIg. 2. (Color online) (a) Absorption coefficient and (b) Tauc plots of $\mathrm{TiO}_{2}$ and $\mathrm{N}$-doped $\mathrm{TiO}_{2}$ films.

plasma is used without $\mathrm{O}_{2}$ gas, as in procedures $2-5$, Ti $2 p$ peaks appear at 457 and $463 \mathrm{eV}$ [as shown in Figs. 3(c)-3(f)], which are attributed to $\mathrm{Ti}_{2} \mathrm{O}_{3}\left(\mathrm{Ti}^{3+}\right) .{ }^{36}$ The appearance of the $\mathrm{Ti}^{3+}$ peaks coincides with the shifting of the bandgap in Fig. 2, suggesting that the $\mathrm{Ti}^{3+}$ peaks appear when the nitrogen content is increased in the films. While small peaks corresponding to $\mathrm{Ti}^{4+}$ and $\mathrm{TiO}$ also appear in Figs. 3(c)-3(f) for procedures $2-5$ that only used a $\mathrm{N}_{2}$ plasma, ${ }^{22}$ the $\mathrm{Ti}^{3+}$ peaks clearly dominate. This change from $\mathrm{Ti}^{4+}$ to $\mathrm{Ti}^{3+}$ is consistent with the film composition information obtained by XPS and reported in Table III. While surface contamination is expected to influence the measured composition values somewhat, a clear reduction in the $\mathrm{O} / \mathrm{Ti}$ ratio from approximately 2.3 for the procedures that employed an $\mathrm{O}_{2}$ plasma (procedures 1 and $\mathrm{TiO}_{2}$ ) to approximately $1.8-2$ for procedures $2-5$ that only used a $\mathrm{N}_{2}$ plasma is seen in Table III. This coincides with the introduction of nitrogen concentrations of 14 to 23 at. \%, which are also reported in Table III.

Figure 4 shows that N1s XPS peaks are present for all procedures that employed the $\mathrm{N}_{2}$ plasma, confirming that nitrogen is incorporated successfully into the $\mathrm{TiO}_{2}$ lattice. It is generally agreed that N1s XPS peaks in the ranges of 396 
TABLE II. Literature data on the XPS binding energies (eV) of Ti 2p, N1s, and O1s (Ref. 27).

\begin{tabular}{|c|c|c|c|c|}
\hline Films & $\operatorname{Ti} 2 p^{3 / 2}$ & $\operatorname{Ti} 2 p^{1 / 2}$ & N1s & O1s \\
\hline $\mathrm{TiN}$ & 455.2 (Ref. 28) & 461 (Ref. 20) & 396 (Ref. 29), 397 (Ref. 30) & Ti-O 531 (Ref. 28) \\
\hline TiNO & 455.2 (Ref. 31) & 461 (Ref. 31) & 397 (Ref. 30) & Ti-O 531 (Ref. 28) \\
\hline $\mathrm{N}$-doped $\mathrm{TiO}_{2}$ & $\begin{array}{c}456-459 \\
\text { (Ref. 29) } \\
459.1 \text { (Ref. 32) }\end{array}$ & $\begin{array}{l}463-465 \\
\text { (Ref. 29) }\end{array}$ & $\begin{array}{c}\text { Ti-N (396) (Refs. } 33 \text { and 34) } \\
\text { O-Ti-N (398) (Ref. 34) } \\
\text { Ti-O-N (400) (Ref. 35) }\end{array}$ & $\begin{array}{c}\text { Ti-O } 529.7 \text { (Ref. 28) } \\
\text { OH } 531 \text { (Ref. 20) }\end{array}$ \\
\hline \multirow[t]{6}{*}{ This work } & Procedure 1: 458.5 & 464 & Ti-N 396 Ti-O-N 400 & Ti-O 529.7 OH 531 \\
\hline & Procedure 2: 457 & 464 & Ti-N 396 O-Ti-N 398 Ti-O-N 400 & Ti-O 529.4 OH 530.1 \\
\hline & Procedure 3: 457 & 463 & Ti-N 396 O-Ti-N 398 & Ti-O 529.7 OH 530 \\
\hline & Procedure 4: 457.4 & 462.5 & Ti-N 396 O-Ti-N 398 Ti-O-N 400 & Ti-O 529.4 OH 530.1 \\
\hline & Procedure 5: 457 & 463 & Ti-N 396 O-Ti-N 398 Ti-O-N 400 & Ti-O 529.3 OH 530.1 \\
\hline & $\mathrm{TiO}_{2}: 458.5$ & 464 & - & Ti-O 529.6 OH 530 \\
\hline
\end{tabular}

to 398 and 399 to $402 \mathrm{eV}$ correspond to substitutional nitrogen and interstitial nitrogen (or chemisorbed species), respectively. ${ }^{37}$ Figure 4 (a) shows a weak interstitial $\mathrm{N}$ peak (Ti-O-N) at $400 \mathrm{eV}$ and a weak peak at $402 \mathrm{eV}$ for the $\mathrm{TiO}_{2}$ procedure, which are attributed to chemisorbed $\mathrm{N}_{2}$ (Refs. 15 and 33). Procedure 1, which employed $3 \mathrm{~s}_{2}$ and $\mathrm{N}_{2}$ plasmas, shows a small interstitial peak (Ti-O-N) at approximately $400 \mathrm{eV}$ in Fig. 4(b), as well as a weak substitutional peak at $396 \mathrm{eV}$ (labeled "Ti-N"). The N1s XPS spectra of the films produced using a $\mathrm{N}_{2}$ plasma only (procedures 2-5) are shown in Figs. 4(c)-4(f) and demonstrate substitutional peaks at approximately 396 and $398 \mathrm{eV}$, as well as interstitial nitrogen peaks at approximately $400 \mathrm{eV}$. It was noted by Viswanathan and Krishanmurthy that if nitrogen assumes anionic substitutional states in $\mathrm{TiO}_{2}$, a binding energy of around $394 \mathrm{eV}$ is expected, whereas $400 \mathrm{eV}$ would be expected for cationic states. ${ }^{37}$ They explained that if the Ti$\mathrm{N}$ bond were to assume covalent character, the binding energy could vary with the extent of loading and possibly account for the variation in binding energy values reported in the literature, such as the two peaks at 396 and $398 \mathrm{eV}$ observed in this work. Sathish et al., for example, attributed a substitutional peak at $398 \mathrm{eV}$ to anionic $\mathrm{N}^{-}$in O-Ti-N linkages. $^{29}$ Thus, the distinction between these two peaks is
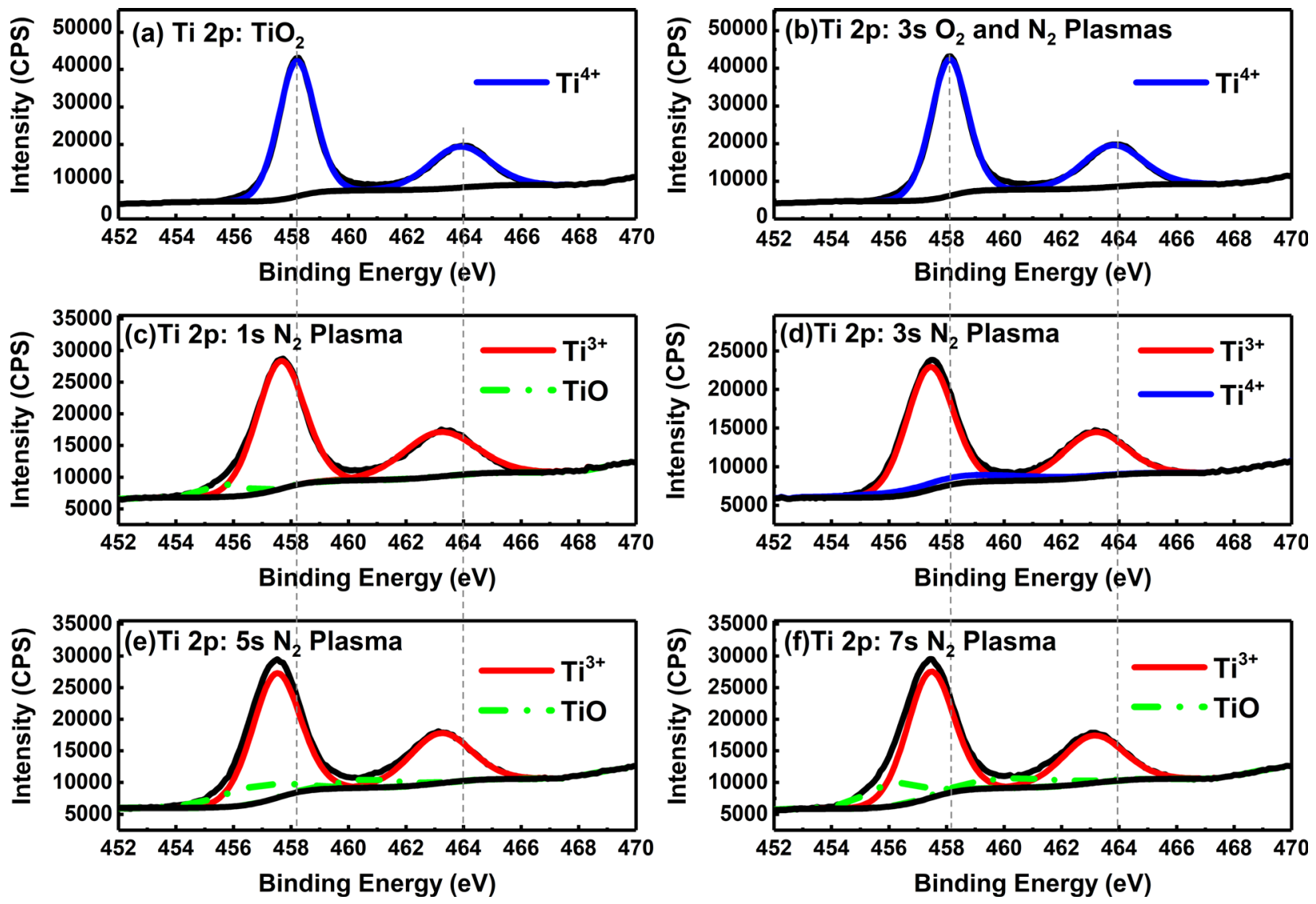

FIG. 3. (Color online) Ti 2p XPS spectra of $\mathrm{TiO}_{2}$ and $\mathrm{N}$-doped $\mathrm{TiO}_{2}$ films: (a) $\mathrm{TiO}_{2}$, (b) $3 \mathrm{~s} \mathrm{O}_{2} / \mathrm{N}_{2}$ plasmas, (c) $1 \mathrm{~s}$ N $\mathrm{N}_{2}$ plasma, (d) $3 \mathrm{~s} \mathrm{~N}_{2}$ plasma, (e) $5 \mathrm{~s} \mathrm{~N}_{2}$ plasma, and (f) $7 \mathrm{~s} \mathrm{~N}_{2}$ plasma. CPS, counts per second. 
TABLE III. Film compositions of PAALD samples.

\begin{tabular}{|c|c|c|c|c|c|c|c|c|}
\hline \multirow[b]{2}{*}{ Procedure } & \multicolumn{6}{|c|}{ Film compositions (at. \%) } & \multicolumn{2}{|c|}{ Fraction $(\%)^{\mathrm{a}}$} \\
\hline & $\mathrm{Ti}$ & $\mathrm{O}$ & $\mathrm{N}$ & $\mathrm{C}$ & $\mathrm{N} / \mathrm{Ti}$ & $\mathrm{O} / \mathrm{Ti}$ & $\mathrm{N}_{\text {inte }}$ & $\mathrm{N}_{\text {sub }}$ \\
\hline 1 & $23.6 \pm 0.2$ & $56.0 \pm 0.4$ & $0.4 \pm 0.2$ & $20.0 \pm 0.5$ & 0.02 & 2.37 & 88 & 12 \\
\hline 2 & $17.4 \pm 0.4$ & $36.0 \pm 0.3$ & $14.4 \pm 0.3$ & $32.0 \pm 0.3$ & 0.82 & 2.06 & 17 & 83 \\
\hline 3 & $13.1 \pm 1.0$ & $26.0 \pm 0.1$ & $23.0 \pm 0.5$ & $37.8 \pm 0.4$ & 1.75 & 1.98 & 0 & 100 \\
\hline 4 & $19.3 \pm 0.3$ & $35.0 \pm 0.3$ & $19.0 \pm 0.4$ & $26.8 \pm 0.8$ & 0.98 & 1.81 & 8 & 92 \\
\hline 5 & $19.8 \pm 0.4$ & $36.0 \pm 0.5$ & $15.7 \pm 0.5$ & $27.8 \pm 0.5$ & 0.79 & 1.81 & 7 & 93 \\
\hline $\mathrm{TiO}_{2}$ & $24.0 \pm 0.6$ & $55.0 \pm 0.3$ & 0 & $21.0 \pm 0.7$ & 0 & 2.30 & - & - \\
\hline
\end{tabular}

${ }^{a}$ Calculated based on the area of the $\mathrm{N}_{\text {interstitial }}$ and $\mathrm{N}_{\text {substitutional }}$ peaks, compared to the total area of the N1s peaks.

unclear and warrants further study; however, within the scope of this work, it is sufficient to ascribe these two peaks to substitutional nitrogen, in agreement with the existing literature. The relative intensities of these two substitutional peaks have been reported to be different for different fabrication processes. ${ }^{37}$ The substitutional peak at $398 \mathrm{eV}$, which is attributed to the $\mathrm{N}^{-}$anion, is expected to be responsible for changing the $\mathrm{Ti}^{4+}$ valence state. ${ }^{37}$ This agrees with our measurements, as it is seen that procedure $3\left(3 \mathrm{~s} \mathrm{~N}_{2}\right.$ plasma) had the most dominant $398 \mathrm{eV}$ peak [Fig. 4(d)] and resulted in $\mathrm{Ti}$ $2 p$ XPS spectra consisting almost exclusively of a $\mathrm{Ti}^{3+}$ signal [Fig. 3(d)]. Only the substitutional nitrogen peaks at 396 and $398 \mathrm{eV}$ are present for the $3 \mathrm{~s}_{2}$ plasma exposure (procedure 3) in Fig. 4(d), whereas an interstitial (Ti-O-N) peak is also present for the $1 \mathrm{~s}, 5 \mathrm{~s}$, and $7 \mathrm{~s} \mathrm{~N}_{2}$ plasma exposures in Figs. 4(c), 4(e), and 4(f). The fraction of the N1s signal attributable to interstitial and substitutional nitrogen is calculated based on the area under the corresponding XPS peaks and reported in Table III, with $100 \%$ substitutional doping observed for the $3 \mathrm{~s} \mathrm{~N}_{2}$ plasma (procedure 3).

The nitrogen concentration and $\mathrm{N} / \mathrm{Ti}$ ratio reported in Table III display similar trends as the ratio of substitutional to interstitial doping. Both increase to their maximum values when the $\mathrm{N}_{2}$ plasma time is increased from $1 \mathrm{~s}$ (procedure 2)
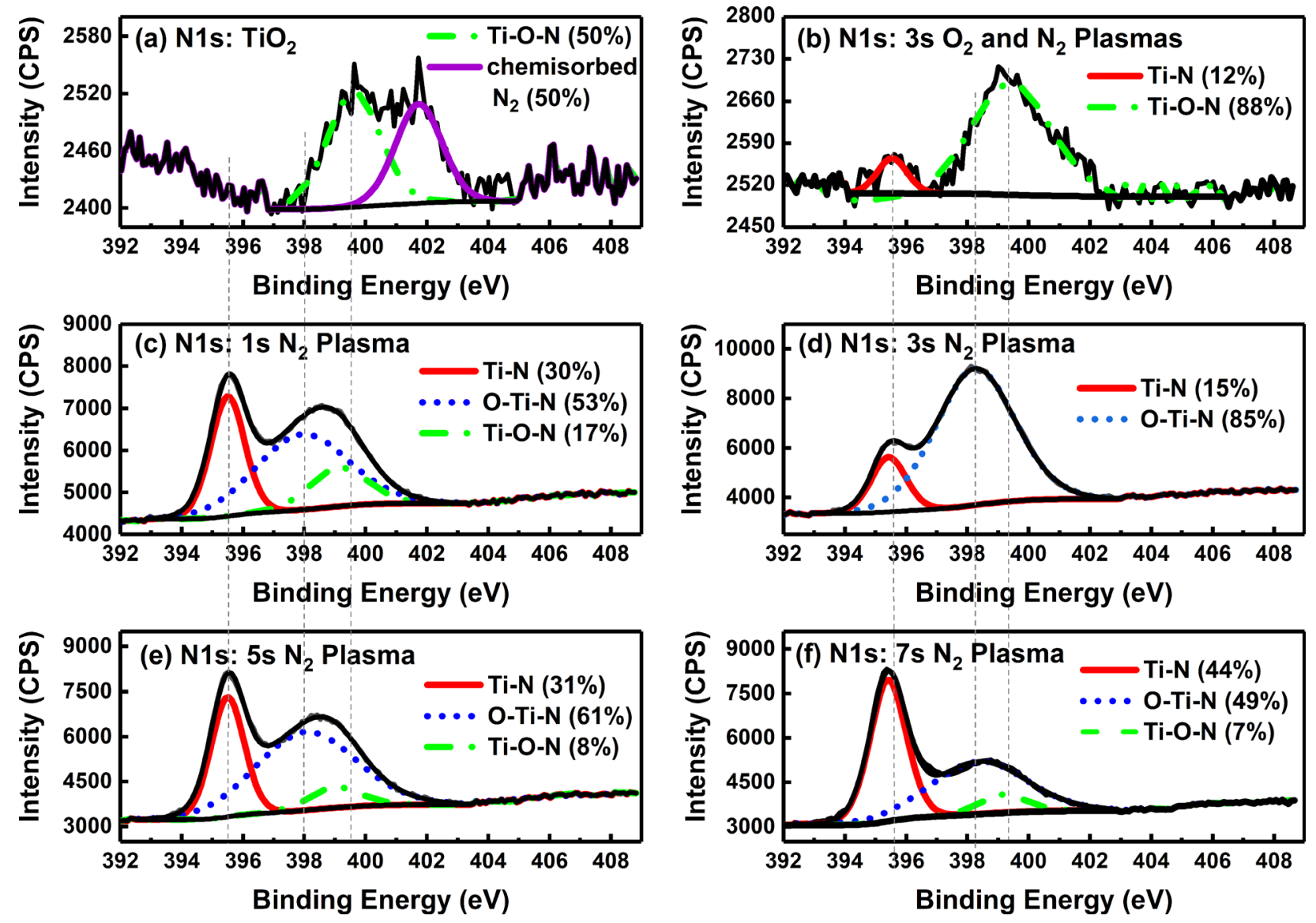

FIG. 4. (Color online) N1s XPS spectra of $\mathrm{TiO}_{2}$ and $\mathrm{N}$-doped $\mathrm{TiO}_{2}$ films: (a) $\mathrm{TiO}_{2}$, (b) $3 \mathrm{~s} \mathrm{O}_{2} / \mathrm{N}_{2}$ plasmas, (c) $1 \mathrm{~s}$ N 2 plasma, (d) $3 \mathrm{~s} \mathrm{~N}_{2}$ plasma, (e) $5 \mathrm{~s} \mathrm{~N}_{2}$ plasma, and (f) $7 \mathrm{~s} \mathrm{~N}_{2}$ plasma. 
to $3 \mathrm{~s}$ (procedure 3 ) and then decrease for longer plasma times (procedures 4 and 5). For example, the nitrogen content increases from $14.4 \pm 0.3$ at. $\%$ to $23.2 \pm 0.5$ at. $\%$ when the $\mathrm{N}_{2}$ plasma exposure is increased from $1 \mathrm{~s}$ to $3 \mathrm{~s}$ and then decreases to $19.0 \pm 0.4$ at. $\%$ and $15.7 \pm 0.5$ at. $\%$ for longer $\mathrm{N}_{2}$ plasma exposure times of $5 \mathrm{~s}$ and $7 \mathrm{~s}$. These results suggest that approximately $3 \mathrm{~s}$ is required for the $\mathrm{N}_{2}$ plasma to react with the monolayer of the Ti precursor. The thicknesses of the samples were measured by ellipsometry to be $23.1 \pm 0.1 \mathrm{~nm}$ for the $3 \mathrm{~s} \mathrm{O}_{2}$ and $\mathrm{N}_{2}$ plasmas (procedure 1), only $11.7 \pm 0.2 \mathrm{~nm}$ for the $1 \mathrm{~s} \mathrm{~N}_{2}$ plasma (procedure 2), $22.3 \pm 0.1 \mathrm{~nm}$ for the $3 \mathrm{~s} \quad \mathrm{~N}_{2}$ plasma (procedure 3), $18.5 \pm 0.4 \mathrm{~nm}$ for the $5 \mathrm{~s} \mathrm{~N}_{2}$ plasma (procedure 4), $18.5 \pm 0.1 \mathrm{~nm}$ for the $7 \mathrm{~s} \mathrm{~N}_{2}$ plasma (procedure 5), and $26 \pm 0.2 \mathrm{~nm}$ for the $\mathrm{TiO}_{2}$ procedure. The $11.7 \mathrm{~nm}$ thickness obtained using 600 cycles of procedure 1 confirms that $1 \mathrm{~s}$ of $\mathrm{N}_{2}$ plasma exposure is insufficient. The decreased nitrogen concentration, decreased N/Ti ratio, and reduced fraction of substitutional doping observed for the $5 \mathrm{~s}$ and $7 \mathrm{~s} \mathrm{~N}_{2}$ plasma exposures, compared to the $3 \mathrm{~s}$ exposure, suggest that for $\mathrm{N}_{2}$ plasma exposure times longer than $3 \mathrm{~s}$, formed Ti-N bonds may be broken by subsequent thermodynamically favored titanium-oxygen reactions. Figure 5 plots the fraction of substitutional and interstitial nitrogen as a function of $\mathrm{N}_{2}$ plasma exposure time. It appears that for extended plasma exposures, reactions between the titanium precursor and residual water in the chamber may result in nitrogen atoms being moved from substitutional to interstitial positions, as oxygen atoms take their place, and then gradually expelled from the films altogether.

The location of nitrogen atoms in the $\mathrm{TiO}_{2}$ lattice is important for catalyst performance ${ }^{38}$ and can also influence the bandgap. ${ }^{36}$ Figure 5 also plots the bandgap as a function of the $\mathrm{N}_{2}$ plasma exposure. It is seen that the trend in the bandgap narrowing is similar to the increase in substitutional nitrogen doping. Notably, the $100 \%$ substitutional doping achieved using procedure $3\left(3 \mathrm{~s} \mathrm{~N}_{2}\right.$ plasma) is higher than that reported previously for PAALD. ${ }^{17}$ The fraction of interstitial doping can be increased by increasing the $\mathrm{N}_{2}$ plasma exposure time or introducing an $\mathrm{O}_{2}$ plasma.

The nitrogen concentration of $23.2 \pm 0.5$ at. $\%$ that is observed for the film deposited using $3 \mathrm{~s} \quad \mathrm{~N}_{2}$ plasma

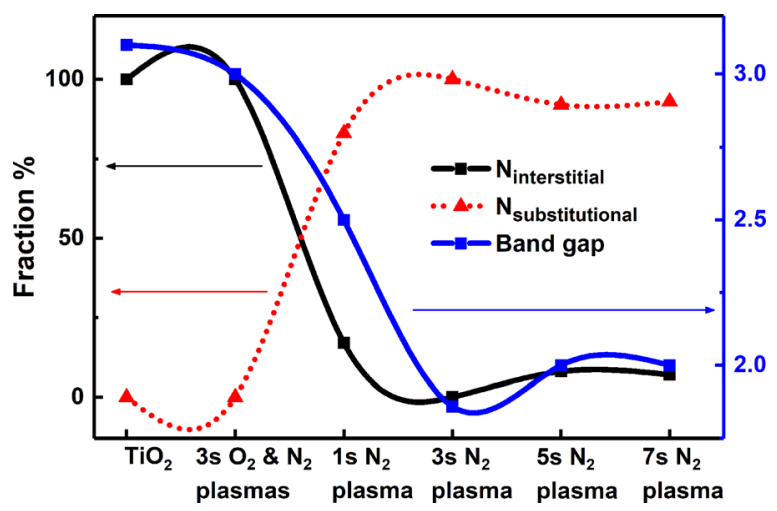

FIG. 5. (Color online) $\mathrm{N}_{\text {interstitial }}$ and $\mathrm{N}_{\text {substitutional peak intensities with the }}$ bandgap. exposures is higher than that reported previously for PAALD of $\mathrm{N}$-doped $\mathrm{TiO}_{2} \cdot{ }^{17,19,20}$ Furthermore, procedure 3 uses a $\mathrm{N}_{2}$ plasma exposure time that is five times shorter than that used by Zhang et al. ${ }^{17}$ to produce a nitrogen content of 13 at. $\%$ at the film surface ( 22 at. $\%$ in the bulk). The resulting cycle time $(10.5 \mathrm{~s} /$ cycle $)$ is three times shorter than that used by Zhang et al. ${ }^{17}$ as shown in Fig. 1. This procedure also demonstrates the ability of a $\mathrm{N}_{2}$ plasma environment to dope $\mathrm{TiO}_{2}$ more effectively, particularly in a substitutional manner, than some plasma environments that make use of $\mathrm{NH}_{3} .{ }^{39}$ The carbon contamination observed in Table III is consistent with previous reports that used TIIP and oxygen plasma. ${ }^{40}$ It may be due to incomplete reaction between the TIIP and the nitrogen plasma, which could leave significant amounts of unreacted precursors. Zhang et al. ${ }^{17}$ also observed a significant amount of carbon (33 at. \%), similar to the amount observed in this work, due to the incomplete reaction of TDMAT with nitrogen. Air contamination resulting from transporting the samples to the XPS equipment is also expected. Finally, Fig. 6 shows the O1s peaks for the samples made using the $\mathrm{TiO}_{2}$ procedure and
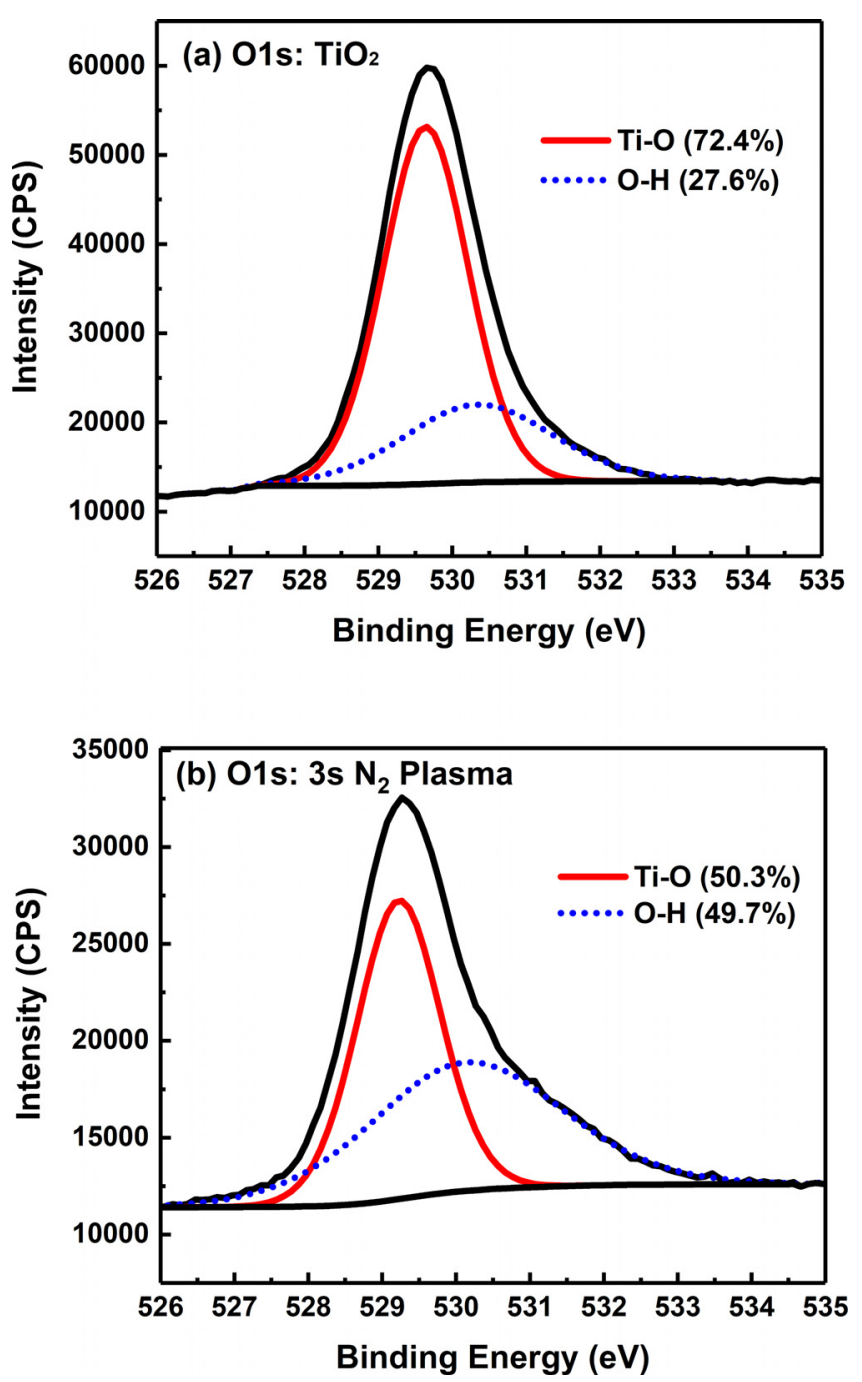

FIG. 6. (Color online) O1s XPS spectra of (a) $\mathrm{TiO}_{2}$ and (b) $\mathrm{N}$-doped $\mathrm{TiO}_{2}$ made using $3 \mathrm{~s} \mathrm{~N}_{2}$ plasma exposures. 
procedure 3 ( $3 \mathrm{~s} \mathrm{~N}_{2}$ plasma). The very high affinity of titanium for oxygen ${ }^{41}$ is expected to result in the $\mathrm{Ti}$ precursor atoms accommodating available oxygen in the chamber. By using a procedure with no $\mathrm{O}_{2}$ plasma (procedure 3 ), the Ti-O bond intensity was decreased, as shown in Fig. 6(b). The O$\mathrm{H}$ signal is attributed to hydroxyl groups on the surface of the films. It is expected that by limiting the formation of $\mathrm{Ti}-\mathrm{O}$ bonds, it was possible to incorporate more nitrogen atoms into the films (substitutional and interstitial) via exposure to the nitrogen plasma.

\section{SUMMARY AND CONCLUSIONS}

A simple and fast PAALD technique to dope $\mathrm{TiO}_{2}$ with nitrogen was demonstrated. UV-visible measurements showed narrowing of the bandgap from 3.1 to $1.9 \mathrm{eV}$. XPS characterization demonstrated a higher nitrogen content $(23 \pm 0.5$ at. $\%)$ than reported previously for nitrogen doping with PAALD although carbon and oxygen contamination influenced this measured value. This method required no $\mathrm{O}_{2}$ precursor, high temperatures, or postchemical treatments to enhance the nitrogen content in the $\mathrm{TiO}_{2}$ films. It required only one reactant plasma with a short exposure time (1 to $7 \mathrm{~s})$. Furthermore, it was demonstrated that the nitrogen doping could be tailored from $100 \%$ substitutional to almost entirely interstitial doping by varying the plasma exposure time.

\section{ACKNOWLEDGMENTS}

A.A. would like to acknowledge Prince Sattam bin Abdul Aziz University, Alkharj, Saudi Arabia, for financial support. The University of Waterloo's Quantum NanoFab was used for device fabrication. The Quantum NanoFab acknowledges support from the Canada Foundation for Innovation, the Ontario Ministry of Research and Innovation, Industry, Canada, and Mike and Ophelia Lazaradis.

${ }^{1}$ J. Bai and B. Zhou, Chem. Rev. 114, 10131 (2014).

${ }^{2}$ M. Grätzel, J. Sol-Gel Sci. Technol. 22, 7 (2001).

${ }^{3}$ I. P. Parkin and R. G. Palgrave, J. Mater. Chem. 15, 1689 (2005).

${ }^{4}$ A. Kafizas and I. P. Parkin, J. Mater. Chem. 20, 2157 (2010).

${ }^{5}$ K. Vasu, M. B. Sreedhara, J. Ghatak, and C. Rao, ACS Appl. Mater. Interfaces 8, 7897 (2016).

${ }^{6}$ B. Liu, L. Wen, and X. Zhao, Sol. Energy Mater. Sol. Cells 92, 1 (2008).

${ }^{7}$ Y. Suda, H. Kawasaki, T. Ueda, and T. Ohshima, Thin Solid Films 453, 162 (2004).

${ }^{8}$ V. Pore, A. Rahtu, M. Leskelä, M. Ritala, T. Sajavaara, and J. Keinonen, Chem. Vap. Deposition 10, 143 (2004).

${ }^{9}$ L. Aarik, T. Arroval, R. Rammula, H. Mändar, V. Sammelselg, and J. Aarik, Thin Solid Films 542, 100 (2013).
${ }^{10}$ V. Pore, T. Kivelä, M. Ritala, and M. Leskelä, Dalton Trans. 0, 6467 (2008).

${ }^{11}$ J. Löckinger, S. Nishiwaki, T. P. Weiss, B. Bissig, Y. E. Romanyuk, S. Buecheler, and A. N. Tiwari, Sol. Energy Mater. Sol. Cells 174, 397 (2018).

${ }^{12}$ A. Sasinska, D. Bialuschewski, M. M. Islam, T. Singh, M. Deo, and S. Mathur, J. Phys. Chem. C 121, 15538 (2017).

${ }^{13}$ Y. Zhang, C. Guerra-Nuñez, I. Utke, J. Michler, P. Agrawal, M. D. Rossell, and R. Erni, Chem. Mater. 29, 2232 (2017).

${ }^{14}$ V. Pore, M. Heikkilä, M. Ritala, M. Leskelä, and S. Areva, J. Photochem. Photobiol., A 177, 68 (2006).

${ }^{15}$ H. Cheng, W. Lee, C. Hsu, M. Hon, and C. Huang, Electrochem. SolidState Lett. 11, 81 (2008).

${ }^{16}$ Y. Zhang, Q. Ma, L. Gao, and E. J. Hensen, Appl. Surf. Sci. 282, 174 (2013).

${ }^{17}$ Y. Zhang, M. Creatore, Q. Ma, A. El Boukili, L. Gao, M. A. Verheijen, and E. J. Hensen, Appl. Surf. Sci. 330, 476 (2015).

${ }^{18}$ H. B. Profijt, S. E. Potts, M. Van de Sanden, and W. Kessels, J. Vac. Sci. Technol., A 29, 050801 (2011).

${ }^{19}$ R. Zhipeng, W. Jun, L. Chaobo, C. Bo, L. Jian, H. Chengqiang, and X. Yang, Plasma Sci. Technol. 16, 239 (2014).

${ }^{20}$ S. Deng et al., J. Vac. Sci. Technol., A 32, 01123 (2014).

${ }^{21}$ A. Goossens, E. Maloney, and J. Schoonman, Chem. Vap. Deposition 4, 109 (1998).

${ }^{22}$ J. Rodriguez, M. Gomez, J. Ederth, G. A. Niklasson, and C. G. Granqvist, Thin Solid Films 365, 119 (2000).

${ }^{23}$ P. Wu, C. Ma, and J. K. Shang, Appl. Phys. A 81, 1411 (2005).

${ }^{24}$ R. López and R. Gómez, J. Sol-Gel Sci. Technol. 61, 1 (2012).

${ }^{25}$ J. Tauc, R. Grigorovici, and A. Vancu, Phys. Status Solidi B 15, 627 (1966).

${ }^{26}$ J. Barth, R. L. Johnson, and M. Cardona, Handbook of Optical Constants of Solids II, edited by E. Palik (Academic, New York, 1991).

${ }^{27}$ C. Chen, H. Bai, and C. Chang, J. Phys. Chem. C 111, 15228 (2007).

${ }^{28}$ N. C. Saha and H. G. Tompkins, J. Appl. Phys. 72, 3072 (1992).

${ }^{29}$ L. Miao, S. Tanemura, H. Watanabe, Y. Mori, K. Kaneko, and S. Toh, J. Cryst. Growth 260, 118 (2004).

${ }^{30}$ G. A. Battiston, R. Gerbasi, A. Gregori, M. Porchia, S. Cattarin, and G. A. Rizzi, Thin Solid Films 371, 126 (2000).

${ }^{31}$ J. Guillot, A. Jouaiti, L. Imhoff, B. Domenichini, O. Heintz, S. Zerkout, A. Mosser, and S. Bourgeois, Surf. Interface Anal. 33, 577 (2002).

${ }^{32}$ M. Maeda and T. Watanabe, J. Electrochem. Soc 153, 186 (2006).

${ }^{33}$ R. Asahi, T. Morikawa, T. Ohwaki, K. Aoki, and Y. Taga, Science 293, 269 (2001).

${ }^{34}$ M. Sathish, B. Viswanathan, R. P. Viswanath, and C. S. Gopinath, Chem. Mater. 17, 6349 (2005).

${ }^{35}$ J. Wang, D. N. Tafen, J. P. Lewis, Z. Hong, A. Manivannan, M. Zhi, M. Li, and N. Wu, J. Am. Chem. Soc. 131, 12290 (2009).

${ }^{36}$ J. Lynch, C. Giannini, J. K. Cooper, A. Loiudice, I. D. Sharp, and R. Buonsanti, J. Phys. Chem. C 119, 7443 (2015).

${ }^{37}$ B. Viswanathan and K. R. Krishanmurthy, Int. J. Photoenergy 2012, 269654 (2012).

${ }^{38}$ S. A. Ansari, M. M. Khan, M. O. Ansari, and M. H. Cho, New J. Chem. 40, 3000 (2016).

${ }^{39}$ D. J. Pulsipher, I. T. Martin, and E. R. Fisher, ACS Appl. Mater. Interfaces 2, 1743 (2010).

${ }^{40}$ J. Musschoot, "Advantages and challenges of plasma enhanced atomic layer deposition,” Ph.D. thesis (University Gent, 2011).

${ }^{41}$ Titanium: A Technical Guide, edited by M. J. Donachie (ASM International, US, 2000).

${ }^{42}$ See supplementary material at https://doi.org/10.1116/1.5019170 for reflectance, transmittance, and refractive index measurements for the films. 